\title{
Correction to: Dryline characteristics in North America's historical and future climates
}

\author{
Lucia Scaff ${ }^{1}$ - Andreas F. Prein ${ }^{2}$ - Yanping Li ${ }^{1}$ - Adam J. Clark ${ }^{3,4}$. Sebastian A. Krogh ${ }^{5,6} \cdot$ Neil Taylor $^{7}$. Changhai Liu ${ }^{2}$.

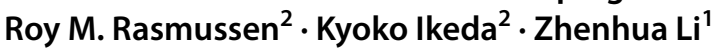

Published online: 7 July 2021

(c) Springer-Verlag GmbH Germany, part of Springer Nature 2021

\section{Correction to: Climate Dynamics \\ https://doi.org/10.1007/s00382-021-05800-1}

In the original publication of the article, the labels for each row that indicate the displayed month are not visible in Fig. 2. The corrected Fig. 2 is shown in this corrigendum.

The original article has been corrected.

The original article can be found online at https://doi.org/10.1007/ s00382-021-05800-1.

Lucia Scaff

lucia.scaff@usask.ca

1 Global Institute for Water Security, University of Saskatchewan, 11 Innovation Blvd, Saskatoon, SK S7N 3H5, Canada

2 NCAR National Center for Atmospheric Research, 3090 Center Green Drive, Boulder, CO 80301, USA

3 NOAA/OAR/National Severe Storms Laboratory, National Weather Center, Norman, OK 73072, USA
4 School of Meteorology, University of Oklahoma, Norman OK 73072, USA

5 Departamento de Recursos Hídricos, Facultad de Ingeniería Agrícola, Universidad de Concepción, 3812120 Chillán, Chile

6 Department of Natural Resources and Environmental Science, University of Nevada, Reno, NV 89557, USA

7 National Lab-West, Meteorological Service of Canada, Environment and Climate Change Canada, Edmonton, AB T6B 1K5, Canada 

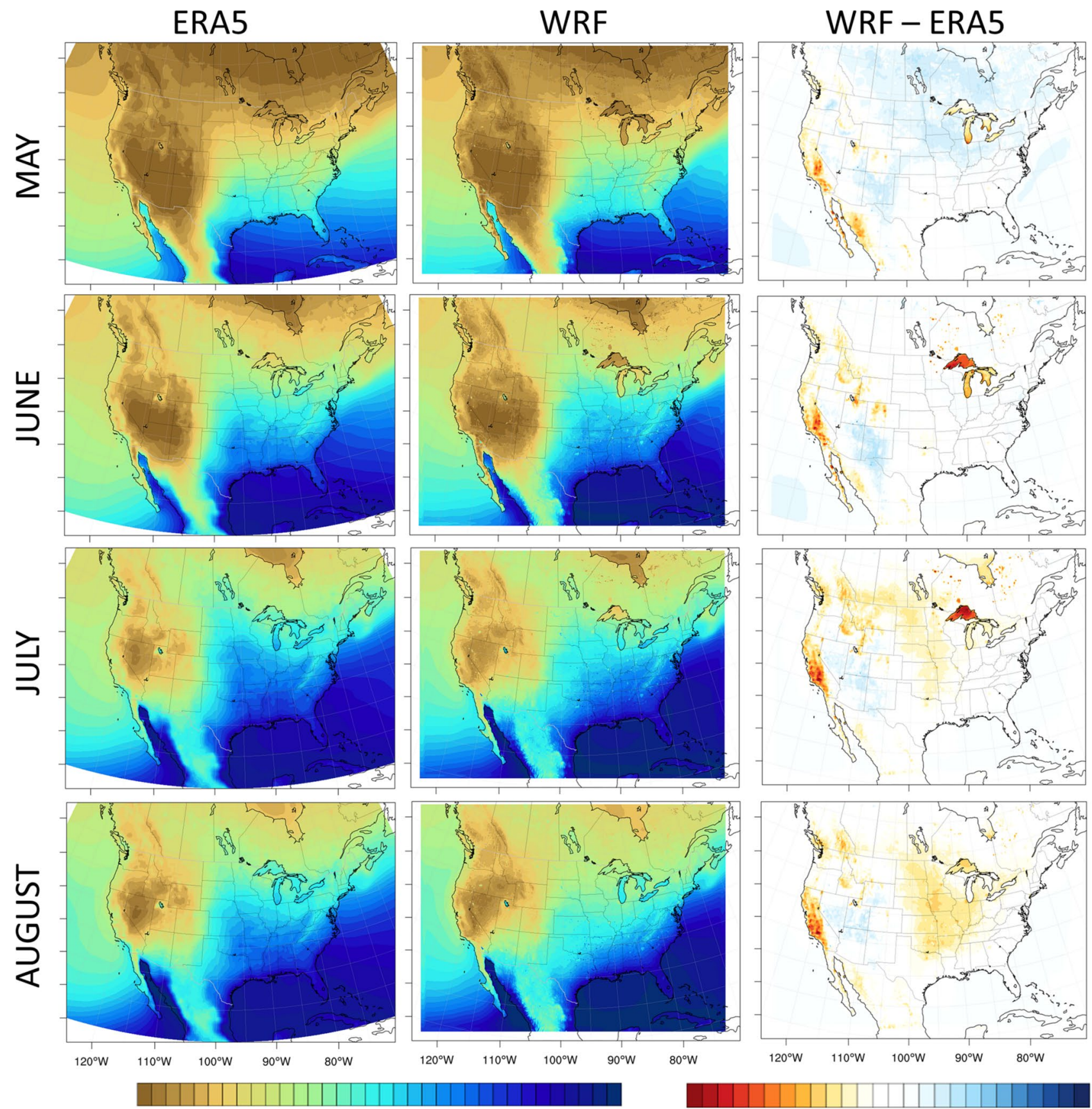

$\begin{array}{llllllllllllllllll}4 & 5 & 6 & 7 & 8 & 9 & 10 & 11 & 12 & 13 & 14 & 15 & 16 & 17 & 18 & 19 & 20\end{array}$ Water vapor mixing ratio $\left(\mathrm{g} \mathrm{kg}^{-1}\right)$

Fig. 2 Water vapor mixing ratio of 13-years monthly average. Left column shows ERA5 reanalysis, the central column shows WRF CTRL simulation, and the right column shows the difference in percentage

Publisher's Note Springer Nature remains neutral with regard to jurisdictional claims in published maps and institutional affiliations. 